\title{
SCIENTIFIC REPORTS

\section{OPEN The Prognostic Implications of Tumor Infiltrating Lymphocytes in Colorectal Cancer: A Systematic Review and Meta-Analysis}

\author{
Gregory E. Idos $\mathbb{1}^{1 *}$, Janet Kwok ${ }^{2}$, Nirupama Bonthala ${ }^{3}$, Lynn Kysh ${ }^{4}$, Stephen B. Gruber ${ }^{1}$ \&
} Chenxu Qu $\mathbf{u}^{2}$

Tumor-infiltrating lymphocytes (TILs) are an important histopathologic feature of colorectal cancer that confer prognostic information. Previous clinical and epidemiologic studies have found that the presence and quantification of tumor-infiltrating lymphocytes are significantly associated with diseasespecific and overall survival in colorectal cancer. We performed a systematic review and meta-analysis, establishing pooled estimates for survival outcomes based on the presence of TILs in colon cancer. PubMed (Medline), Embase, Cochrane Library, Web of Science, and ClinicalTrials.gov were searched from inception to April 2017. Studies were included, in which the prognostic significance of intratumoral tumor infiltrating lymphocytes, as well as subsets of CD3, CD8, FOXP3, CD45R0 lymphocytes, were determined within the solid tumor center, the invasive margin, and tumor stroma. Random-effects models were calculated to estimated summary effects using hazard ratios. Forty-three relevant studies describing 21,015 patients were included in our meta-analysis. The results demonstrate that high levels of generalized TILS as compared to low levels had an improved overall survival (OS) with a HR of 0.65 $(p=<0.01)$. In addition, histologically localized CD3+T-cells at the tumor center were significantly associated with better disease-free survival $(H R=0.46,95 \% \mathrm{Cl} 0.36-0.61, p=0.05)$, and $C D 3+$ cells at the invasive margin were associated with improved disease-free survival ( $\mathrm{HR}=0.57,95 \% \mathrm{Cl} 0.38-0.86$, $\mathrm{p}=0.05)$. CD8 $+\mathrm{T}$-cells at the tumor center had statistically significant prognostic value on cancerspecific survival and overall survival with HRs of $0.65(p=0.02)$ and $0.71(p<0.01)$, respectively. Lastly, FOXP3 + T-cells at the tumor center were associated with improved prognosis for cancer-specific survival $(H R=0.65, p<0.01)$ and overall survival $(H R=0.70, p<0.01)$. These findings suggest that TILs and specific TIL subsets serve as prognostic biomarkers for colorectal cancer.

Although advances in screening and treatment have substantially improved survival from colorectal cancer (CRC), clinical outcomes vary widely among patients with tumors diagnosed at the same TNM stage, and disease relapse occurs in $20-30 \%$ of patients with localized cancer ${ }^{1}$. The presence of microsatellite instability (MSI-H) in colorectal cancers have a better prognosis as compared to microsatellite stable (MSS) colorectal cancer ${ }^{2-5}$. The mechanisms that confer this benefit are not fully understood, but an association has been linked to the prominent infiltration of immune cells within the tumor ${ }^{6}$. Increased focus on the tumor microenvironment has identified inflammatory activity as a critical predictor of disease activity impacting patient prognosis.

The host immune response has been implicated in tumor behavior as it influences all phases of tumor development and growth ${ }^{7-9}$. Tumor-infiltrating lymphocytes (TILs) in histopathological analysis of CRC is often interpreted as the host protecting against tumor development ${ }^{10,11}$. TILs mediate recruitment, maturation, and activation of immune cells that suppress tumor growth. Tumor infiltration by $\mathrm{T}$ lymphocytes is a highly informative prognostic factor for CRC outcome, independent of traditional prognostic indicators ${ }^{12-14}$. Numerous studies have demonstrated that the type, density and site of tumor-infiltrating lymphocytes in primary tumors are prognostic for disease-free survival (DFS) and overall survival (OS) from CRC and hints at a fundamental function of the immune system in the tumor microenvironment ${ }^{15-18}$.

${ }^{1}$ City of Hope National Medical Center, Duarte, CA, USA. ${ }^{2}$ University of Southern California Norris Comprehensive Cancer Center, Los Angeles, CA, USA. ${ }^{3}$ Cedars Sinai Medical Center, Los Angeles, California, USA. ${ }^{4}$ Institute of Nursing and Interprofessional Research (INIR), Children's Hospital, Los Angeles, CA, USA. *email: gidos@coh.org 
However, variability in study design, outcomes, sample size, and methods of measuring the host immune response reflecting the heterogeneity of studies in the literature inspired this systematic analysis. Recently, large retrospective studies have reported their data on the prognostic performance of TIL in CRC survival. To obtain a more precise estimate of the effect in populations with CRC, we performed an updated systematic review and meta-analysis to measure the impact of TILs on CRC survival.

\section{Methods}

Protocol and registration. We developed a protocol based on standard guidelines for the systematic review of prognostic studies and followed suggestions on updating systematic reviews as outlined by Moher et al. ${ }^{19}$. We followed the Preferred Reporting Items for Systematic Reviews and Meta-Analyses (PRISMA) statements for reporting our systematic review ${ }^{20}$. Methods of the analysis and inclusion criteria were specified a priori in a protocol.

Data sources and search strategy. A librarian (LK) developed searches using a combination of keywords and controlled vocabulary (when available) in the following databases: PubMed (Appendix 1), Embase (Appendix 2 \& 3), initially through OvidSP and later via Elsevier, Cochrane Library (Appendix 4), Web of Science (Appendix 5), and ClinicalTrials.gov (1997 to April 2017). In addition, we search grey literature sources (https// www.usa.gov, https://scholar.google.com) to identify relevant publications. The English language filter was used when available. We also examined bibliographies of related papers and reviews, while also consulting with experts in the field. In addition, we evaluated reference lists of previously published systematic reviews and meta-analysis.

Eligibility criteria. All studies were reviewed initially based on title and abstract. If the data was insufficient based on title and abstract, the full text article would be reviewed. Two independent reviewers (GEI and NB) reviewed the first 100 results of the Ovid Medline search to assess for agreement of article selection with a kappa of 0.82 . Then further search results were divided equally amongst GI and NB. Disagreement was resolved either by discussion, consensus or by a third party (SBG).

For study inclusion, the keywords included focused on generalized tumor inflammatory infiltrate and associated T lymphocytes' subsets (CD4, CD8) in colorectal cancer patients identified with hematoxylin and eosin stain (HE) or immunohistochemical staining (IHC) and reported prognostic information. IHC staining was evaluated in subgroup analysis for tumor center (CC) and tumor stroma (TS) and at the invasive tumor margin (IM). Prognostic information included overall survival (OS) and disease-free survival (DFS).

Exclusion criteria included those publications for which there was insufficient data to estimate a hazard ratio (HR) with a 95\% confidence interval (CI). However, references from review articles, case reports, commentaries and letter were reviewed to identify any additional studies that met the inclusion criteria. An effort was made to contact the authors for any clarifications.

Data extraction and quality assessment. Two reviewers (GEI, JK) independently evaluated and extracted relevant information from each included study. We utilized a form originally developed from the work of McShane et al. ${ }^{21}$ and Hayes et al. ${ }^{22}$ adapted by Mei et al..$^{18}$ for quality assessment in their systematic review and meta-analysis as this adaptation was comprehensive (See Supplement 1). It resulted in a quality rating of 0-9 based on reporting of inclusion and exclusion criteria, study design (prospective or retrospective), patient and tumor characteristics, description of the method or assay, study endpoints, follow-up time with patients and number of patients that dropped out during the follow-up period ${ }^{18}$.

Data collection process. A standardized data abstraction form was adapted from Mei et al. to include key elements pertaining to the study design, sample size, patient age, stage of disease, assay method, follow-up duration, and HR estimates (with the corresponding 95\% CIs) for TILs at certain locations within tumors (CT, TS or IM) and the HR cutoff point, method of quantifying (immunohistochemistry, PCR, sequencing). For time-to-event outcomes, we retrieved and curated the HR estimates with 95\% CI from the original articles ${ }^{18}$. Discrepancies in interpretation between reviewers (GEI, NB) were resolved by discussion with a third reviewer (SBG) to reach consensus.

Subgroup analyses. We performed analyses to estimate the association between prognostic outcomes (OS, CS, DFS) and both T-lymphocyte subsets $(\mathrm{CD} 3+, \mathrm{CD} 8+, \mathrm{FOXP} 3+, \mathrm{CD} 45 \mathrm{R} 0+)$ and T lymphocyte infiltrate location (CC, TS, or IM). Survival time was recorded from either the date of diagnosis or the initiation of treatment, as available from the published reports. Random effects models were used consistent with prior published meta-analyses that showed evidence of heterogeneity for similar subgroup analyses.

Summary measures. Meta-analyses were performed using the R package 'meta' version 4.9-0, using statistical software $\mathrm{R}$ (version 3.4.3). Random effects models were calculated based on HR estimates and their standard errors; inverse weighting was used for pooled variance. We then plotted forest and funnel charts by T-cell type, T-cell source and outcome to evaluate for publication bias. Interstudy heterogeneity was quantified using the $I^{2}$ statistic, with an $I^{2}$ value $>50 \%$ as our a priori threshold for substantial heterogeneity ${ }^{23}$.

\section{Results}

Literature search. Eligible studies were identified and selected as shown in Fig. 1. Among the 3,789 studies identified for initial evaluation, 1,963 studies were eligible for further assessment based on pre-specified criteria. Abstracts of these studies were reviewed and 1,804 studies were excluded for the reasons delineated in Fig. 1. 


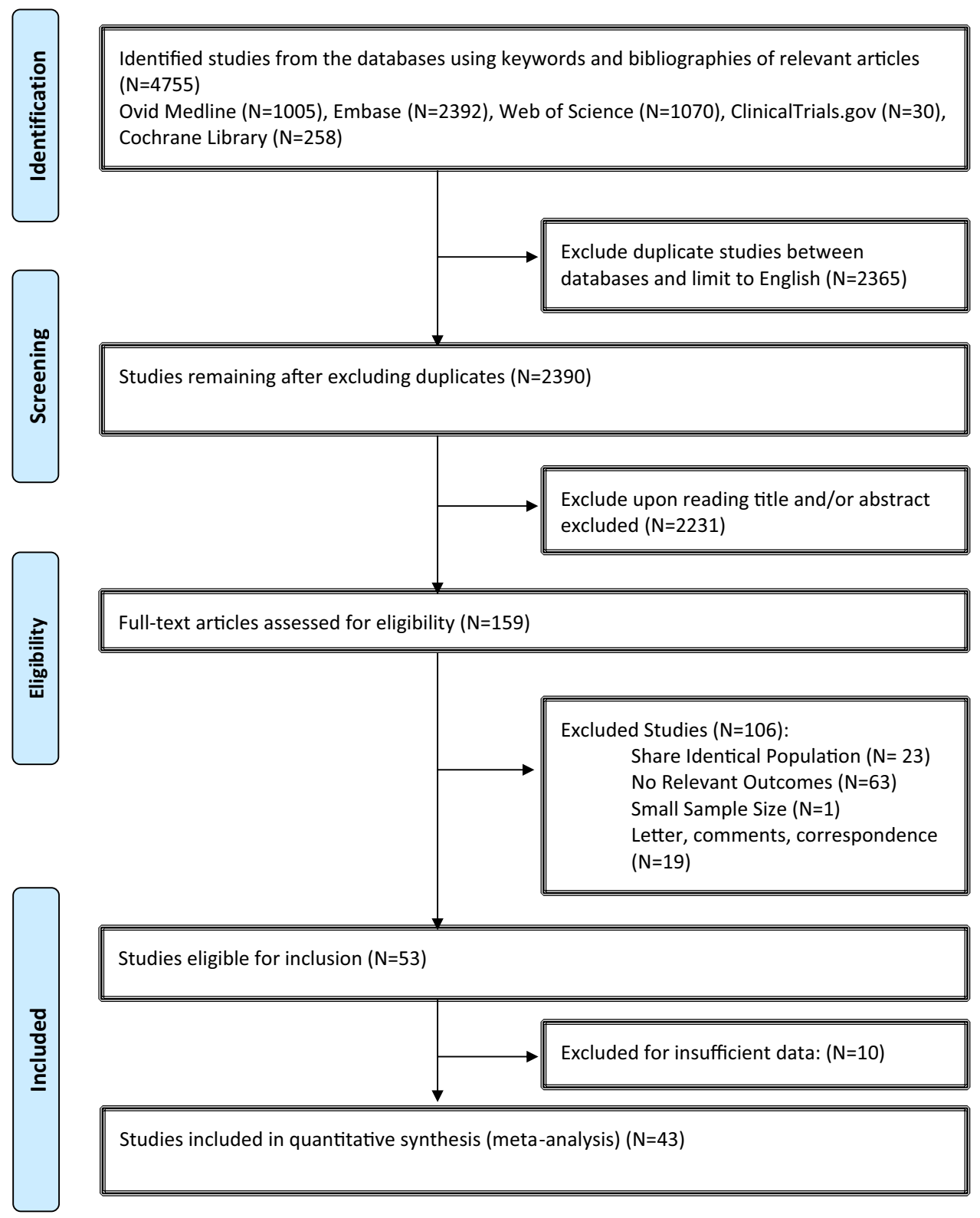

Figure 1. TIL Meta-Analysis Flow Diagram.

After abstract review, we identified 159 articles for full manuscript review and 106 of these studies were excluded. The most common reasons for exclusion were studies were the following: No relevant outcome $(\mathrm{N}=63)$; Shared identical population $(\mathrm{N}=23)$; and Editorial, letter, or commentary $(\mathrm{N}=19)$. There were 53 studies eligible for inclusion, but 10 studies were found to have insufficient data. Therefore, 43 studies were included in the final meta-analysis (Table 1$)^{24-65}$.

Study characteristics. Characteristics for each study are summarized in Table 1. Forty-three studies had a median quality score of 6 out of 9 (range: 3-8) and consisted of a median of 243 patients (range: 42-2,369), with a median follow-up of 64 months (range: 18-240). All studies were published from 1997-2017. There was one study included from an abstract due to the large number of patients $(\mathrm{N}=2,293)$ included in the retrospective study (Sinicrope et al ${ }^{64}$ ). Study sample sizes range from 42 to 2,396 patients representing an overall total of 21,015 patients. HRs and 95\% CI for overall survival (OS), cancer-specific survival (CSS), or disease-free survival (DFS) were derived directly when available. A synopsis of study variables and results are summarized in Table 1 and Table 2, respectively.

Subgroup analysis. Prognostic effect estimates were pooled for generalized tumor inflammatory infiltrate counts and T-lymphocyte subsets stratified by tumor location (IM, TS, CC) in CRC. Due to limited numbers and low sample sizes of studies within each subset, estimates of between-study heterogeneity were imprecise. Therefore, we performed funnel plot analyses for both generalized tumor inflammatory infiltrates and T-cell subsets. 


\begin{tabular}{|c|c|c|c|c|c|c|}
\hline Year & First Author & $\begin{array}{l}\text { Counting } \\
\text { Site }\end{array}$ & T-cell Subset & Outcomes & Assay & Variables \\
\hline 1997 & Ropponen & General & TIL & OS & HE & $\begin{array}{l}\text { Age, sex, site, surgical treatment, post-op } \\
\text { complications, histology }\end{array}$ \\
\hline 1998 & Naito & IM & CD8 & OS & IHC & Pattern on invasion, histological type \\
\hline 1999 & Nielsen & General & TIL & OS & IHC & Grade, site \\
\hline 2001 & Guidoboni & $\mathrm{CC}$ & CD3, CD8, GRB & DFS, OS & IHC & $\begin{array}{l}\text { Age, sex, pathologic stage, grade, histology, ploidy, } \\
\text { adjuvant chemo, life status, recurrence }\end{array}$ \\
\hline 2001 & Nagtegaal & General & $\mathrm{CD} 3, \mathrm{CD} 4, \mathrm{CD} 8$ & OS & $\mathrm{IHC} / \mathrm{HE}$ & N/A \\
\hline 2001 & Paraf & $\mathrm{CC}$ & $\mathrm{CD} 3$ & OS & IHC & $\begin{array}{l}\text { Age, tumor size, expanding margin, CLR, tumor } \\
\text { site, differentiation, pTNM stage, vascular and } \\
\text { perineural invasion, peripheral adenomatous } \\
\text { residue }\end{array}$ \\
\hline 2002 & Cianchi & General & TIL & os & Histopath & $\begin{array}{l}\text { Age, sex, histotype, tumor differentiation, depth } \\
\text { of invasion, venous invasion, character of invasive } \\
\text { margin, conspicuous lymphocytic infiltration, } \\
\text { tumor relapse }\end{array}$ \\
\hline 2004 & Chiba & CC & CD8 & CSS & IHC & Ki67, site, invasion pattern, differentiation \\
\hline 2004 & Menon & IM & $\mathrm{CD} 45$ & DFS & IHC/HE & $\begin{array}{l}\text { Age, sex, location, stage, differentiation, mucinous, } \\
\text { BM-like, recurrence }\end{array}$ \\
\hline 2004 & Prall & CC & CD8 & CSS, OS & $\mathrm{IHC} / \mathrm{HE}$ & Location, substage, adjuvant therapy, MSI \\
\hline 2005 & Buckowitz & General & TIL & OS & HE & $\begin{array}{l}\text { Age, clinical criteria, treatment, localization, stage, } \\
\text { T, N, M, Crohn's like reaction, survival }\end{array}$ \\
\hline 2005 & Gao & General & TIL & OS & HE & $\begin{array}{l}\text { Gender, age, tumor location, Duke's stage, growth } \\
\text { pattern, differentiation, DNA ploidy, S-phase } \\
\text { fraction, p53 expression }\end{array}$ \\
\hline 2005 & Klintrup & General & TIL & OS & $\mathrm{HE}$ & Duke’s stage, WHO grade, tumor location \\
\hline 2006 & Galon & CC & CD3 CT/IM pattern & OS & IHC & TNM, differentiation \\
\hline 2009 & Ogino & General & TIL & CSS, OS & IHC & $\begin{array}{l}\text { BMI, lymph node count, KRAS, BRAF, p53, PTGS2, } \\
\text { MSI, CIMP, LINE-1 methylation }\end{array}$ \\
\hline 2009 & Roxburgh & General & $\mathrm{CD} 3$ & os & $\mathrm{IHC} / \mathrm{HE}$ & $\begin{array}{l}\text { ki67, pi16, tumor differentiation, serosal } \\
\text { involvement, margin involvement, tumor } \\
\text { perforation, venous invasion, mGPS }\end{array}$ \\
\hline 2009 & Salama & $\mathrm{CC}$ & FOXP3 & CSS & IHC & $\begin{array}{l}\text { Stage, tumor site, histologic grade, vascular } \\
\text { invasion, lymphatic invasion, perineural invasion, } \\
\text { lymphocytic response, MSI }\end{array}$ \\
\hline 2009 & Sinicrope & TS & FoxP3 & OS, DFS & IHC & Histologic grade, tumor site, chemo \\
\hline 2010 & Correale & TS & CD8 CCR7+ & OS & IHC/HE & $\begin{array}{l}\text { Performance status, sex, age, tumor grade, liver } \\
\text { mets }\end{array}$ \\
\hline 2010 & Deschoolmeester & $\mathrm{CC}$ & CD3, CD8, GRB & OS, DFS & IHC & Location, grade, neo-adjuvant, adjuvant, MSI \\
\hline 2010 & Frey & $\mathrm{CC}$ & $\mathrm{CD} 3, \mathrm{CD} 8, \mathrm{FOXP} 3$ & CSS & $\mathrm{IHC} / \mathrm{HE}$ & $\begin{array}{l}\text { Age, tumor diameter, tumor location, grade, } \\
\text { histology, vascular invasion, tumor border } \\
\text { configuration }\end{array}$ \\
\hline 2010 & Lee & TS & CD3, CD45RO, FOXP3 & os & IHC & $\begin{array}{l}\text { CEA, size, lymphatic invasion, vascular invasion, } \\
\text { perineural invasion }\end{array}$ \\
\hline 2010 & Nosho & $\mathrm{CC}$ & $\begin{array}{l}\text { CD3, CD8, CD45RO, } \\
\text { FOXP3 }\end{array}$ & OS, CSS & IHC & $\begin{array}{l}\text { BMI, family history, tumor location, tumor grade, } \\
\text { KRAS, BRAF, PIK3CA, MSI, CIMP, LINE-1 } \\
\text { hypomethylation }\end{array}$ \\
\hline 2010 & Peng & General & $\mathrm{CD} 3, \mathrm{CD} 45 \mathrm{RO}$ & OS & IHC & Tumor site, pathologic grade \\
\hline 2010 & Simpson & $\mathrm{CC}$ & CD3 & CSS & IHC & Sex, grade, vascular invasion, site, MHC class I, MSI \\
\hline 2011 & Dahlin & General & $\begin{array}{l}\text { CD3 (MLH1, MSH2, } \\
\text { MSH6, PMS2) }\end{array}$ & CSS & IHC & MSI \\
\hline 2012 & Huh & General & TIL & OS, DFS & HE? & $\begin{array}{l}\text { Age, tumor size, differentiation, lymphovascular } \\
\text { invasion, perineural invasion, preoperative } \\
\text { CEA, macroscopic ulceration, tumor border } \\
\text { configuration }\end{array}$ \\
\hline 2012 & Richards & General & $\begin{array}{l}\text { CD3, CD8, CD45RO, } \\
\text { FOXP3 }\end{array}$ & CSS & HE stain & $\begin{array}{l}\text { Age, sex, elective/emergency, tumor site, anemia, } \\
\text { WBC, SIR(S), K-M, T, N, TNM, Peterson Index }\end{array}$ \\
\hline 2012 & Yoon & $\mathrm{CC}$ & CD8 & OS & IHC & Grade, site \\
\hline 2013 & Kim & $\mathrm{CC}$ & FoxP3 & os & IHC & $\begin{array}{l}\text { Age, gender, level of wall infiltration, lymph node } \\
\text { metastasis }\end{array}$ \\
\hline 2013 & Lewis & General & $\begin{array}{l}\text { CLR (Crohns like } \\
\text { reaction) }\end{array}$ & OS, PFS & $\mathrm{HE}$ & $\begin{array}{l}\text { Lack of dirty necrosis, mucin differentiation, signet } \\
\text { ring cell feature, medullary feature, histological } \\
\text { heterogeneity, background dysplasia, 5-FU based } \\
\text { chemo }\end{array}$ \\
\hline 2014 & Di Caro & IM & CD3 & DFS & $\mathrm{IHC}$ & N/A \\
\hline 2014 & Ling & TS & CD8, FOXP3 & CSS & IHC & MSI, CIMP \\
\hline 2014 & Reimers & $\mathrm{CC}$ & Foxp3 & OS, DFS & TMA, IHC & $\begin{array}{l}\text { Age, gender, tumor grade, adjuvant therapy, } \\
\text { circumferential margin }\end{array}$ \\
\hline
\end{tabular}




\begin{tabular}{|c|c|c|c|c|c|c|}
\hline Year & First Author & $\begin{array}{l}\text { Counting } \\
\text { Site }\end{array}$ & T-cell Subset & Outcomes & Assay & Variables \\
\hline 2014 & Richards & IM & $\begin{array}{l}\text { CD3, CD8, CD45RO, } \\
\text { FOXP3 }\end{array}$ & CSS & IHC & $\begin{array}{l}\text { Preoperative systemic inflammatory response, } \\
\text { Carstairs Deprivation Index, ASA grade, smoking } \\
\text { status, POSSUM physiology scores, tumor } \\
\text { differentiation, venous invasion, tumor necrosis, } \\
\text { adjuvant chemo }\end{array}$ \\
\hline 2015 & Kim & $\mathrm{IM}$ & CD8, CD45RO, FOXP3 & OS & IHC, TMA & $\begin{array}{l}\text { Age, gender, pTNM, lymphatic invasion, distant } \\
\text { metastasis, MSI, CIMP, KRAS, BRAF, tumor } \\
\text { location, adjuvant chemotherapy }\end{array}$ \\
\hline 2015 & Mori & $\mathrm{CC}$ & CD8 & DFS & IHC & NLR, PLR, CRP, MSI \\
\hline 2015 & Reissfelder & $\mathrm{CC}$ & CD4, CD8, FOXP3 & OS & IHC & Gender, UICC, TNM, operative procedure \\
\hline 2015 & Vlad & IM & CD3 & OS & IHC & $\begin{array}{l}\text { Age, tumor location, TNM stage, histological grade, } \\
\text { vascular, lymphatic and perineural invasion }\end{array}$ \\
\hline 2015 & Wang & $\mathrm{CC}$ & FOXP3 & OS & IHC & $\begin{array}{l}\text { Age, gender, tumor size, differentiation, mucinous } \\
\text { type, LN mets, T4, post-op chemo, tumor location, } \\
\text { albumin }\end{array}$ \\
\hline 2016 & Rozek & General & TIL, CLR & OS, CSS & $\mathrm{HE}$ & CLR, grade, MSI \\
\hline 2016 & Sinicrope & General & FoxP3 & DFS, OS & IHC & Histologic grade, tumor site, chemo \\
\hline 2016 & Chen & $\mathrm{CC}$ & $\begin{array}{l}\text { CD3, CD4, CD8, } \\
\text { CD45R0, }\end{array}$ & DFS, OS & IHC & $\begin{array}{l}\text { Age, gender, tumor site, TNM stage, LNR, VELIPI, } \\
\text { tumor diameter, resection margin, differentiation, } \\
\text { histopathology }\end{array}$ \\
\hline
\end{tabular}

Table 1. Summary of study subsets and variables included in analysis.

Generalized tumor infiltrating lymphocytes. Density of generalized tumor infiltrates within CRC were pooled from fourteen studies for analysis (Fig. 2). All studies indicate improved prognosis for the presence of TILs for OS (HR $=0.65$; 95\% CI, 0.58-0.77), CSS ( $\mathrm{HR}=0.58$; 95\% CI, 0.46-0.73), and DFS (HR $=0.72$; 95\% CI, $0.60-0.88)$. There was no indication of publication bias for OS based on funnel plot analysis. However, moderate heterogeneity was noted in the OS subgroup $\left(I^{2}=54 \%, P=0.02\right)$.

CD3+ T lymphocyte subset. The CD3 antigen is a T-cell co-receptor glycoprotein that plays an essential role in adaptive immune response. The association between the presence of CD3 + T lymphocytes and survival of CRC patients was extracted from fourteen studies (Fig. 3) stratified by tumor location, with eleven evaluating the tumor center, four the tumor stroma, and five the IM. The pooled HRs from the tumor center were calculated for OS $(\mathrm{HR}=0.67 ; 95 \% \mathrm{CI}, 0.45-1.00)$, CSS $(\mathrm{HR}=0.79 ; 95 \% \mathrm{CI}, 0.57-1.11)$, and $\mathrm{DFS}(\mathrm{HR}=0.46 ; 95 \%$ CI, 0.36-0.61). Statistically significant heterogeneity was observed between studies in the OS group $\left(I^{2}=86 \%\right.$, $\mathrm{P}<0.01$ ). The pooled HRs from the tumor margin (IM) were calculated for OS (HR $=0.69 ; 95 \% \mathrm{CI}, 0.48-1.00)$, $\mathrm{CSS}(\mathrm{HR}=0.49 ; 95 \% \mathrm{CI}, 0.38-0.63)$, and DFS ( $\mathrm{HR}=0.57 ; 95 \% \mathrm{CI}, 0.38-0.86)$. The pooled HRs from the tumor stroma (TS) were calculated for OS (HR $=0.89 ; 95 \% \mathrm{CI}, 0.49-1.61)$, CSS ( $\mathrm{HR}=0.58 ; 95 \% \mathrm{CI}, 0.45-0.75)$, and DFS $(\mathrm{HR}=0.70 ; 95 \% \mathrm{CI}, 0.27-1.81)$.

CD8+ T lymphocyte subset. CD8+ T cells are cytotoxic T cells that promote apoptosis of cancer cells ${ }^{66}$. The association between the presence of CD8 $+\mathrm{T}$ lymphocytes and survival of CRC patients was extracted from thirteen studies (Fig. 4) stratified by tumor location, with twelve evaluating the tumor center, five the stroma, and five the invasive margin. The pooled HRs from the tumor center were calculated for OS (HR $=0.71 ; 95 \%$ CI, 0.53-0.94), CSS ( $\mathrm{HR}=0.65$; 95\% CI, 0.52-0.80), and DFS ( $\mathrm{HR}=0.32$; 95\% CI, 0.18-0.56). Statistically significant heterogeneity was observed between studies for OS $\left(I^{2}=86 \%, \mathrm{P}<0.01\right)$. The pooled HRs from the IM were calculated for OS $(\mathrm{HR}=0.92 ; 95 \% \mathrm{CI}, 0.82-1.03)$ and $\mathrm{DFS}(\mathrm{HR}=0.61 ; 95 \% \mathrm{CI}, 0.37-1.01)$. The pooled HRs from the TS were calculated for OS ( $\mathrm{HR}=0.73$; 95\% CI, 0.56-0.97) CSS (HR $=0.71 ; 95 \% \mathrm{CI}, 0.55-0.92)$ and DFS $(\mathrm{HR}=1.95 ; 95 \% \mathrm{CI}, 0.66-5.76)$. Estimated HRs for CSS and DFS for CD8 + lymphocyte infiltrates from the tumor stroma were provided from a single study.

FOXP3+ Treg subset. FOXP3+ Tregs suppress aberrant immune response against self-antigens and maintain homeostasis of the immune system ${ }^{67}$. The association between the presence of FOXP3 + T lymphocytes and survival of CRC patients was extracted from fourteen studies (Fig. 5) stratified by tumor location, with eleven evaluating the CC, four the TS, and three the IM. The pooled HRs from the tumor center were calculated for OS $(\mathrm{HR}=0.70 ; 95 \% \mathrm{CI}, 0.57-0.87)$, CSS (HR $=0.66$; 95\% CI, 0.55-0.79) and DFS (HR $=0.75 ; 95 \% \mathrm{CI}, 0.39-1.46)$. The pooled HRs from the IM were calculated for OS $(\mathrm{HR}=0.65 ; 95 \% \mathrm{CI}, 0.49-0.88)$ and CSS $(\mathrm{HR}=0.73 ; 95 \%$ $\mathrm{CI}, 0.56-0.96)$. The pooled HRs from the TS were calculated for OS ( $\mathrm{HR}=0.52 ; 95 \% \mathrm{CI}, 0.27-0.99)$ and DFS $(\mathrm{HR}=0.48 ; 95 \% \mathrm{CI}, 0.21-1.06)$.

CD45R0+ Treg subset. The association between the presence of CD45R0 + T lymphocytes and survival of CRC patients was extracted from four studies (Fig. 6) stratified by tumor location, with three assessing the CC, one the TS, and one the IM. The pooled HR from the tumor center panel were calculated for OS $(\mathrm{HR}=0.59 ; 95 \%$ CI, 0.45-0.78), CSS (HR $=0.51 ; 95 \%$ CI, 0.33-0.80) and DFS ( $\mathrm{HR}=0.13 ; 95 \% \mathrm{CI}, 0.02-1.18)$. Estimated HRs for OS and DFS for CD45R0 + lymphocyte infiltrates from the invasive margin and tumor stroma were provided from single studies. 


\begin{tabular}{|c|c|c|c|c|}
\hline & Location & Overall Survival & $\begin{array}{l}\text { Cancer-Specific } \\
\text { Survival }\end{array}$ & $\begin{array}{l}\text { Disease-Free } \\
\text { Survival }\end{array}$ \\
\hline \multirow[b]{2}{*}{ TIL } & \multirow[b]{2}{*}{ General } & 12 studies & 4 studies & 3 studies \\
\hline & & $\begin{array}{l}\text { HR: } 0.65 \\
95 \% \text { CI: } 0.54-0.77\end{array}$ & $\begin{array}{l}\text { HR: } 0.58 \\
95 \% \text { CI:0.46-0.73 }\end{array}$ & $\begin{array}{l}\text { HR: } 0.72 \\
95 \% \text { CI:0.60-0.88 }\end{array}$ \\
\hline \multirow{4}{*}{ CD3 } & Total Studies & 11 studies & 4 studies & 7 studies \\
\hline & Tumor Center & $\begin{array}{l}\text { HR: } 0.67 \\
\text { 95\% CI:0.45-1.00 }\end{array}$ & $\begin{array}{l}\text { HR: } 0.79 \\
95 \% \text { CI:0.57-1.11 }\end{array}$ & $\begin{array}{l}\text { HR: } 0.46 \\
95 \% \text { CI:0.36-0.61 }\end{array}$ \\
\hline & Invasive Margin & $\begin{array}{l}\text { HR: } 0.69 \\
\text { 95\% CI:048-1.00 }\end{array}$ & $\begin{array}{l}\text { HR: } 0.49 \\
\text { 95\% CI:0.38-0.63 }\end{array}$ & $\begin{array}{l}\text { HR: } 0.57 \\
95 \% \text { CI:0.38-0.86 }\end{array}$ \\
\hline & Stroma & $\begin{array}{l}\text { HR: } 0.89 \\
\text { 95\% CI:0.49-1.61 }\end{array}$ & $\begin{array}{l}\text { HR: } 0.58 \\
95 \% \text { CI:0.45-0.75 }\end{array}$ & $\begin{array}{l}\text { HR: } 0.70 \\
95 \% \text { CI:0.27-1.81 }\end{array}$ \\
\hline \multirow[b]{2}{*}{ CD4 } & Total Studies & 2 studies & & 1 study \\
\hline & Tumor Center & $\begin{array}{l}\text { HR: } 0.83 \\
\text { 95\% CI:0.53-1.30 }\end{array}$ & & $\begin{array}{l}\text { HR: } 0.55 \\
\text { 95\% CI:0.31-0.97 }\end{array}$ \\
\hline \multirow{4}{*}{ CD8 } & Total Studies & 9 studies & 5 studies & 5 studies \\
\hline & Tumor Center & $\begin{array}{l}\text { HR: } 0.71 \\
\text { 95\% CI: } 0.53-0.94\end{array}$ & $\begin{array}{l}\text { HR: } 0.65 \\
95 \% \text { CI:0.52-0.80 }\end{array}$ & $\begin{array}{l}\text { HR: } 0.71 \\
\text { 95\% CI:0.53-0.94 }\end{array}$ \\
\hline & Invasive Margin & $\begin{array}{l}\text { HR: } 0.87 \\
\text { 95\% CI:0.71-1.07 }\end{array}$ & & $\begin{array}{l}\text { HR: } 0.61 \\
95 \% \text { CI:0.37-1.01 }\end{array}$ \\
\hline & Stroma & $\begin{array}{l}\text { HR: } 0.73 \\
95 \% \text { CI:0.56-0.97 }\end{array}$ & $\begin{array}{l}\text { HR: } 0.71 \\
95 \% \text { CI:0.55-0.92 }\end{array}$ & $\begin{array}{l}\text { HR: } 1.95 \\
95 \% \text { CI:0.66-5.76 }\end{array}$ \\
\hline \multirow{4}{*}{ CD45R0 } & Total Studies & 5 studies & 1 studies & 2 studies \\
\hline & Tumor Center & $\begin{array}{l}\text { HR: } 0.59 \\
95 \% \text { CI:0.45-0.78 }\end{array}$ & $\begin{array}{l}\text { HR: } 0.13 \\
\text { 95\% CI:0.02-1.18 }\end{array}$ & $\begin{array}{l}\text { HR: } 0.51 \\
\text { 95\% CI:0.33-0.80 }\end{array}$ \\
\hline & Invasive Margin & $\begin{array}{l}\text { HR: } 0.47 \\
\text { 95\% CI:0.33-0.66 }\end{array}$ & & \\
\hline & Stroma & $\begin{array}{l}\text { HR: } 0.13 \\
\text { 95\% CI:0.02-1.16 }\end{array}$ & & $\begin{array}{l}\text { HR: } 0.20 \\
95 \% \text { CI:0.06-0.71 }\end{array}$ \\
\hline \multirow{5}{*}{ FoxP3 } & Total Studies & 11 studies & 4 studies & 4 studies \\
\hline & Tumor Center & $\begin{array}{l}\text { HR: } 0.70 \\
95 \% \text { CI:0.57-0.87 }\end{array}$ & $\begin{array}{l}\text { HR: } 0.66 \\
95 \% \text { CI:0.55-0.79 }\end{array}$ & $\begin{array}{l}\text { HR: } 0.75 \\
\text { 95\% CI:0.39-1.46 }\end{array}$ \\
\hline & Invasive Margin & $\begin{array}{l}\text { HR: } 0.65 \\
\text { 95\% CI:0.49-0.88 }\end{array}$ & $\begin{array}{l}\text { HR: } 0.73 \\
\text { 95\% CI:0.56-0.96 }\end{array}$ & \\
\hline & Stroma & $\begin{array}{l}\text { HR: } 0.52 \\
95 \% \text { CI:0.27-0.99 }\end{array}$ & & \begin{tabular}{|l|} 
HR: 0.48 \\
95\% CI:0.21-1.06
\end{tabular} \\
\hline & General & $\begin{array}{l}\text { HR:0.53 } \\
\text { 95\% CI:0.24-1.18 }\end{array}$ & $\begin{array}{l}\text { HR: } 0.65 \\
\text { 95\% CI:0.54-0.78 }\end{array}$ & \\
\hline
\end{tabular}

Table 2. Summary of study outcome measures by subset.

\section{Discussion}

We have performed a systematic review and quantitative meta-analysis of the prognostic impact of tumor infiltrating lymphocyte density and composition on CRC outcome. Through a computerized, systematic literature search of Medline, Embase, Web of Science, and Scopus databases using pre-determined inclusion criteria, we identified 43 studies published between August 1997 and April 2017 (representing a total of 21,015 CRC patients with available samples) that evaluate specific marker subset populations of tumor infiltrating lymphocytes in CRC and survival outcomes. We separately considered Generalized TIL density, CD3, CD8, FOXP3, CD45R0 as the focus of our meta-analysis, recognizing that there are other systems of scoring the host immune response that are beyond the scope of the current meta-analysis. Since the publication of an initial meta-analysis of TILs and CRC in 2014 by Mei et al. which included 7840 patients, there have been an additional 13,175 CRC patients with tissue samples that have undergone analysis for TIL density by T-cell subset and histopathologic location. Due to the increasing recognition of intratumoral adaptive immune reaction as a prognostic marker for survival and as a therapeutic target of immune checkpoint inhibitors, we performed an updated systematic review and meta-analysis of TIL.

Pooled analysis from an extensive compilation of studies suggest that high generalized TIL counts and CD3+ T-cell density have the strongest association with survival benefit for patients as compared to low generalized TIL counts and CD3 + T-cell density in regards to disease-free survival (DFS), cancer-specific survival (CSS), and overall survival (OS). The pooled summary HRs for each T-cell subset were inconsistent across different studies. Some markers trended towards a stronger prognostic association with survival as compared to the earlier analysis performed by Mei et al. (CD3, CD8, FOXP3).

The effect of the immune system in colorectal cancer is still being elucidated as several prospective and retrospective studies demonstrate that robust antitumor immunity is associated with favorable prognosis in patients with CRC. Notably, we confirmed in our study a prognostic benefit of FoxP3 + T cell infiltrates which stands in contrast to previous meta-analyses suggesting that tumor-infiltrating FoxP3 + T-cells are associated with poor clinical outcomes in solid cancers ${ }^{68,69}$. Recent studies elucidating the interplay between the tumor microenvironment and colonic microbiome have identified two distinct subpopulations of immunosuppressive and proinflammatory FOXP3 + T-cells. Investigators found that proinflammatory FoxP3 ${ }^{\text {lo }}$ T-cells were associated with an 
A.

Study

Cancer Specific Survival

Ogino 2009

Dahlin 2011

Richards 2012

Rozek 2016

Random effects mode

Heterogeneity: $I^{2}=10 \%, \tau^{2}=0.0072, p=0.34$

Test for effect in subgroup: $z=-5.03(p<0.01)$

Disease Free Survival

Ropponen 1997

Huh 2012

Sinicrope 2016

Random effects mode

Heterogeneity: $I^{2}=0 \%, \tau^{2}=0, p=1.00$

Test for effect in subgroup: $z=-3.23(p<0.01)$

Overall Survival

Ropponen 1997

Nielsen 1999

Nagtegaal 2001

Cianchi 2002

Buckowitz 2005

Gao 2005

Klintrup 2005

Ogino 2009

Roxburgh 2009

Huh 2012

Rozek 2016

Sinicrope 2016

Random effects model

Heterogeneity: $1^{2}=52 \%, \tau^{2}=0.035, p=0.02$

Test for effect in subgroup: $z=-4.62(p<0.01)$

Random effects model

Heterogeneity: $I^{2}=38 \%, \tau^{2}=0.0197, p=0.05$

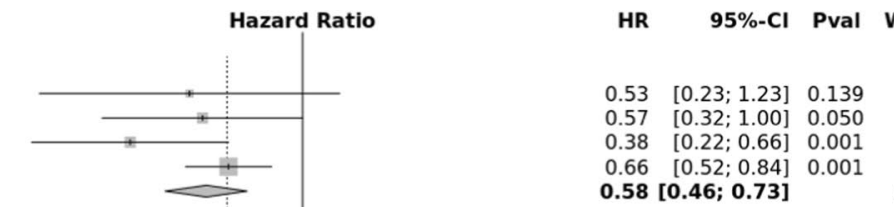

$1.7 \%$

$0.57-[0.32 ; 1.00] \quad 0.050-3.4 \%$

$0.38 \quad[0.22 ; 0.66] \quad 0.001-3.5 \%$

$0.58[0.46 ; 0.73] \quad 18.4 \%$

Test for subgroup differences: $\chi_{2}^{2}=2.07, \mathrm{df}=2(p=0.35 \mathrm{D} .2$

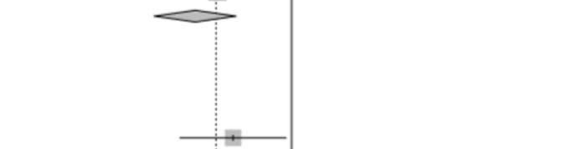

$0.72 \quad[0.53 ; 0.97] \quad 0.031-8.0 \%$

$0.72[0.47 ; 1.11] \quad 0.143 \quad 5.1 \%$

$0.73[0.53 ; 1.01] \quad 0.057 \quad 7.3 \%$

$0.72[0.60 ; 0.88] \quad 20.4 \%$

B.

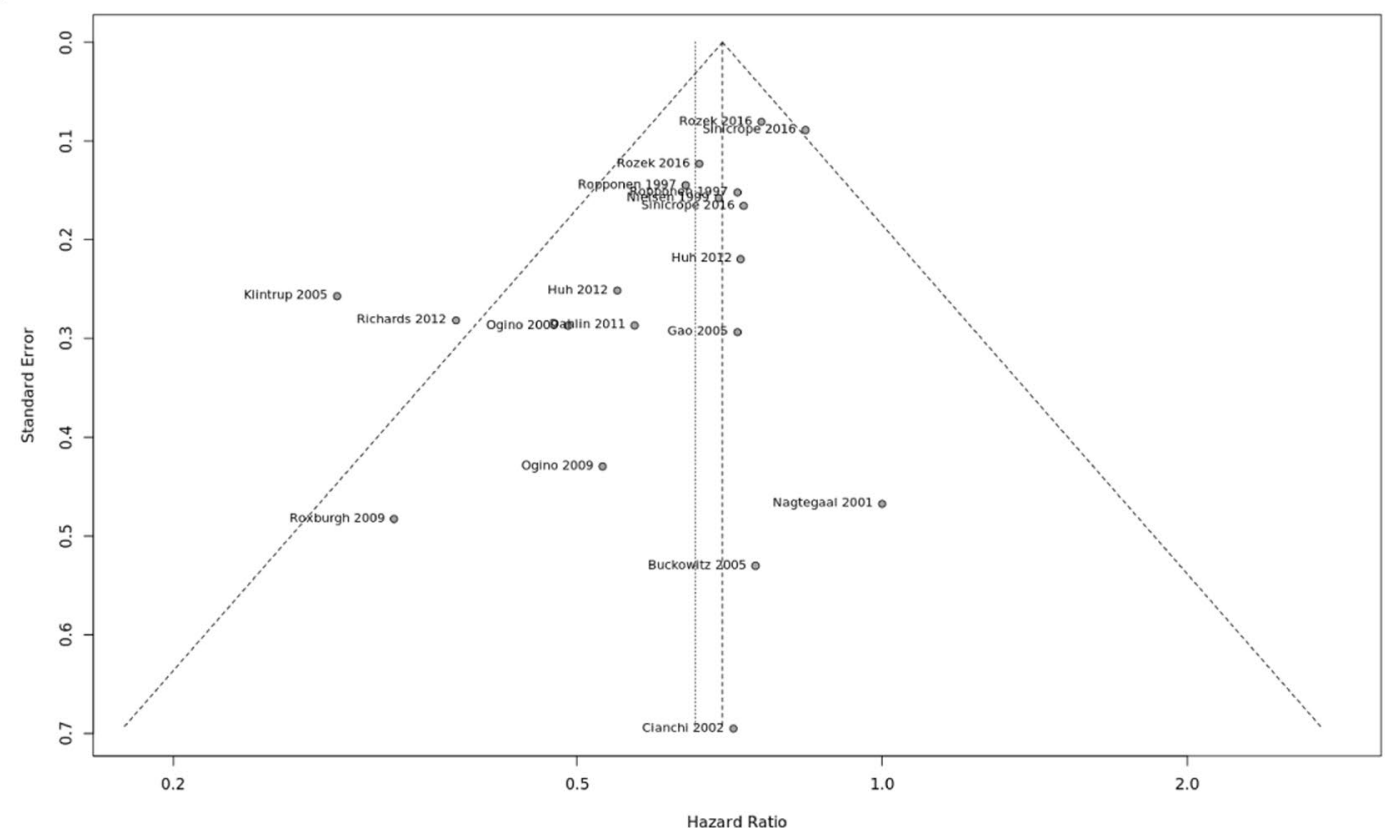

Figure 2. Forest plots of random effects between levels of generalized inflammatory infiltrate and survival. (A) The effect of generalized tumor infiltrate on cancer-specific survival (CSS), disease-free survival (DFS), and overall survival (OS). (B) Funnel plots of meta-analyses to assess the association between TILs and survival.

increased presence of Fusobacterium nucleatum and better CRC patient prognosis, while immunosuppressive FOXP3 + T-cellls were associated with worse outcomes ${ }^{70}$. Additional TIL research is ongoing in understanding the modulation of T-cell trafficking by the gut microbiome and the control of tumor growth through direct lysis of cancer cells through the production of cytokines that promote a cytotoxic response ${ }^{71,72}$. In addition, new immunotherapies are being developed that harness adoptive transfer of marker-specific TIL populations to elicit an immune response to tumors ${ }^{73}$. 
A.

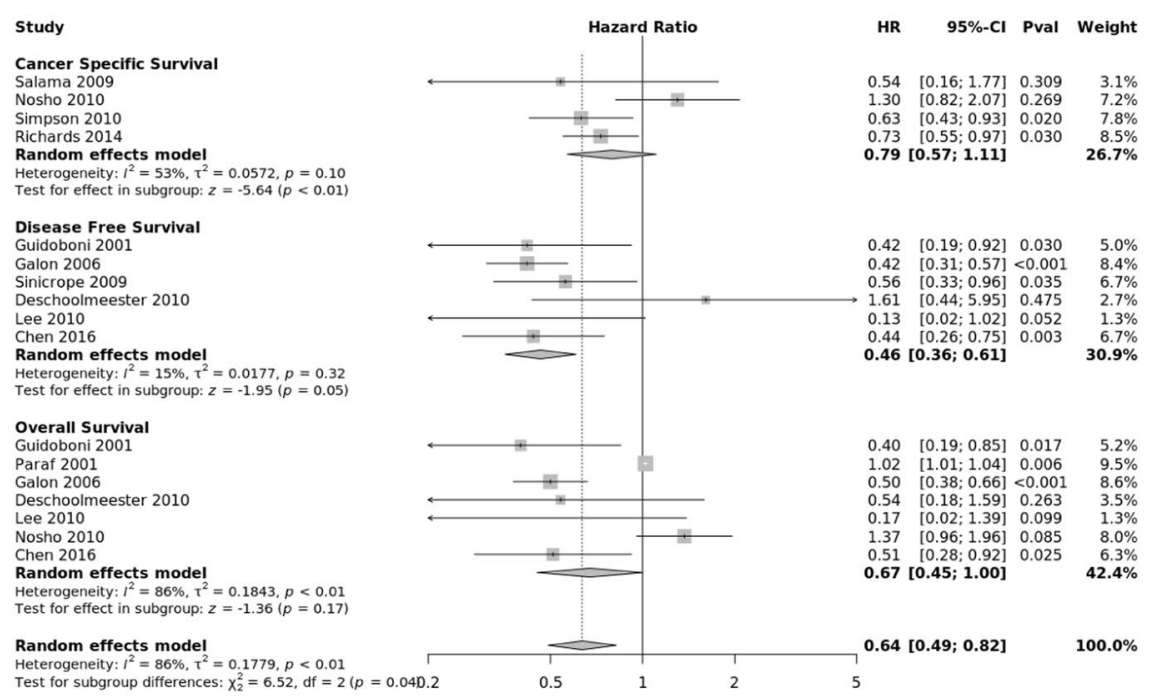

B.

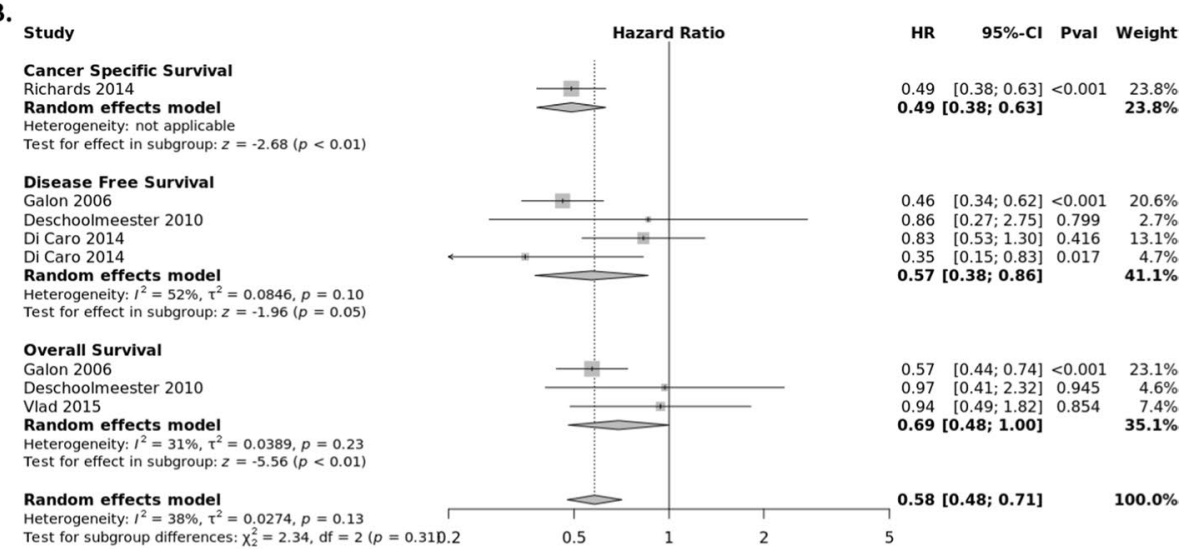

C.

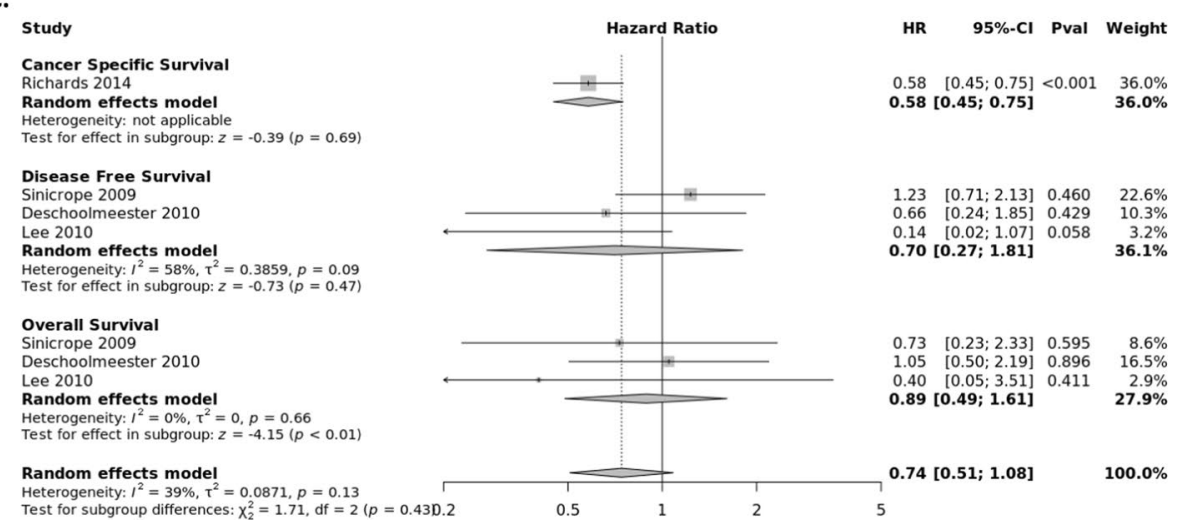

Figure 3. Forest plots of random effects between levels of CD3+ T-cell infiltrate and Survival. The effect of CD3 + T-cells in the (A) tumor center (B) invasive margin (C) stroma on cancer-specific survival (CSS), disease-free survival (DFS), and overall survival (OS).

Our meta-analysis demonstrates that generalized TIL density is a strong prognostic marker for survival in patients with colorectal cancer. This result is concordant with previous studies that identified the association of TILs with increased survival ${ }^{74}$. The strengths of the study include the addition of large retrospective studies by Rozek et al ${ }^{63}$, and Sinicrope et al. ${ }^{64}$, which included 2,369 patients and 2,293 patients respectively, adding further precision and generalizability to the recognition that TILs confer a prognostic advantage with a maximum likelihood $\mathrm{HR}=0.65$ for overall survival. 
A.

Study

Cancer Specific Survival

Chiba 2004

Prall 2004

Salama 2009

Richards 2014

Random effects mode

Heterogeneity: $I^{2}=60 \%, \tau^{2}=0.0303, p=0.04$

Heterogeneity: $I^{2}=60 \%, \tau^{2}=0.0303, p=0.04$
Test for effect in subgroup: $z=-2.40(p=0.02)$

Disease Free Survival

Guidoboni 2001

Deschoolmeester 2010

Mori 2015

Chen 2016

Random effects mode

Heterogeneity: $I^{2}=0 \%, \tau^{2}=0, p=0.46$
Test for effect in subgroup: $z=-3.98(p<0.01)$

Overall Survival

Naito 1998

Guidoboni 2001

Prall 2004

Deschoolmeester 2010

Nosho 2010

Reissfelder 2015

Reissfelder 2018
Chen 2016

Random effects mode

等

$z=-4.10(p<0.01)$

Random effects mode

$\%, \tau^{2}=0.0832, p<0.01$

Test for subgroup differences: $\chi_{2}^{2}=6.36, \mathrm{df}=2(p=0.04 \mathrm{D} .2$

B.

Study

Disease Free Survival

Menon 2004

Deschoolmeester 2010

Random effects mode

Heterogeneity: $I^{2}=0 \%, \tau^{2}=0, p=0.53$

Test for effect in subgroup: $z=-1.51(p=0.13)$

Overall Surviva

Naito 1998

Deschoolmeester 2010

Kim 2015

Random effects mode

Heterogeneity: $I^{2}=0 \%, \tau^{2}=0, p=0.74$

Test for effect in subgroup: $z=-1.93(p=0.05)$

Random effects model

Heterogeneity: $I^{2}=0 \%, \tau^{2}=0, p=0.49$

Test for subgroup differences: $\chi_{1}^{2}=2.43, \mathrm{df}=1(p=0.12 \mathrm{D} .2$

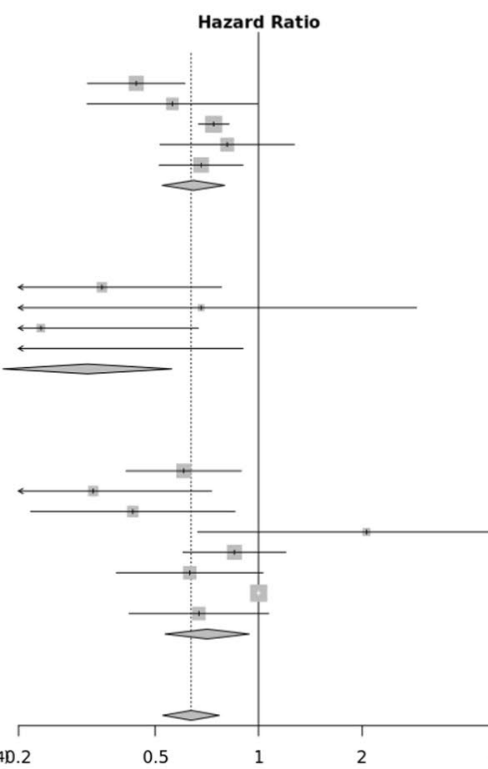

HR

95\%-Cl Pval Weight

$0.44 \quad[0.32: 0.61]<0.001$

$\begin{array}{ll}0.56-[0.32 ; 0.09]<0.001 & 8.4 \%\end{array}$

$0.74 \quad[0.67 ; 0.82]<0.001 \quad 10.9 \%$

$\begin{array}{llll}0.81 & {[0.52 ; 1.27]} & 0.358 & 6.9 \%\end{array}$

$0.65[0.52 ; 0.80] 0.007 \quad 40.8 \%$
$0.35 \quad[0.16 ; 0.78] 0.010$

$0.68 \quad[0.16 ; 2.88] 0.601$

$0.23 \quad[0.08 ; 0.67] \quad 0.007$

$0.09 \quad 0.01 ; 0.90] 0.040$

$0.32[0.18 ; 0.56]$

$0.60 \quad[0.41 ; 0.89] \quad 0.011$ $0.33[0.15 ; 0.73] \quad 0.006$ $0.43[0.22 ; 0.85] \quad 0.016$ $2.06[0.66 ; 6.39] \quad 0.211$ $0.85 \quad[0.60 ; 1.20] \quad 0.356$ $1.00 \quad[0.99 ; 1.01] 1.000$ (1.2\% 0.71 [0.53; 0.94]

$0.64[0.53 ; 0.77]$

$100.0 \%$

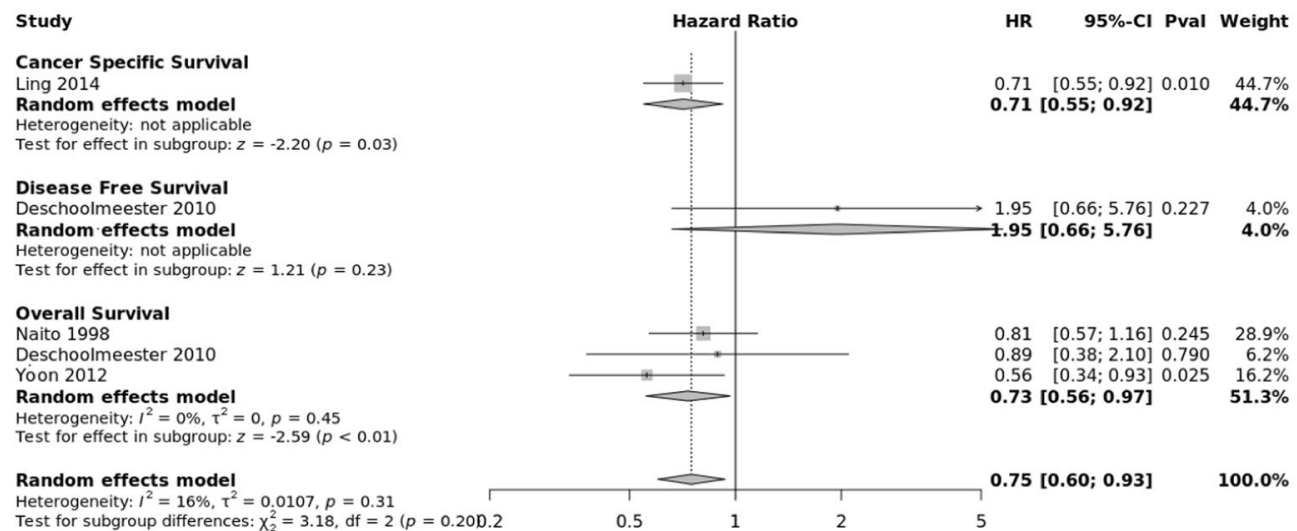

Figure 4. Forest plots of random effects between levels of CD8+ T-cell infiltrate and Survival. The effect of CD8+ T-cells in the (A) tumor center (B) invasive margin (C) stroma on cancer-specific survival (CSS), disease-free survival (DFS), and overall survival (OS).

These findings are consistent with previous meta-analyses ${ }^{18}$, yet our results have caveats that are relevant to this type of summary analysis. Heterogeneity existed in most analyses even though subgroup and overall summary estimates were similar. Also, studies that utilize different methods of TIL identification, small populations, and variations associated with archival specimens were pooled. Nonetheless, the more homogeneous TIL density summary estimates were similar to the overall summary estimates, suggesting that the overall summary measures are a reasonable estimation of prognosis associated with TILs. Second, the meta-analysis was subject to detection, verification and spectrum biases from the original studies. We may have overlooked relevant studies with results 
A.

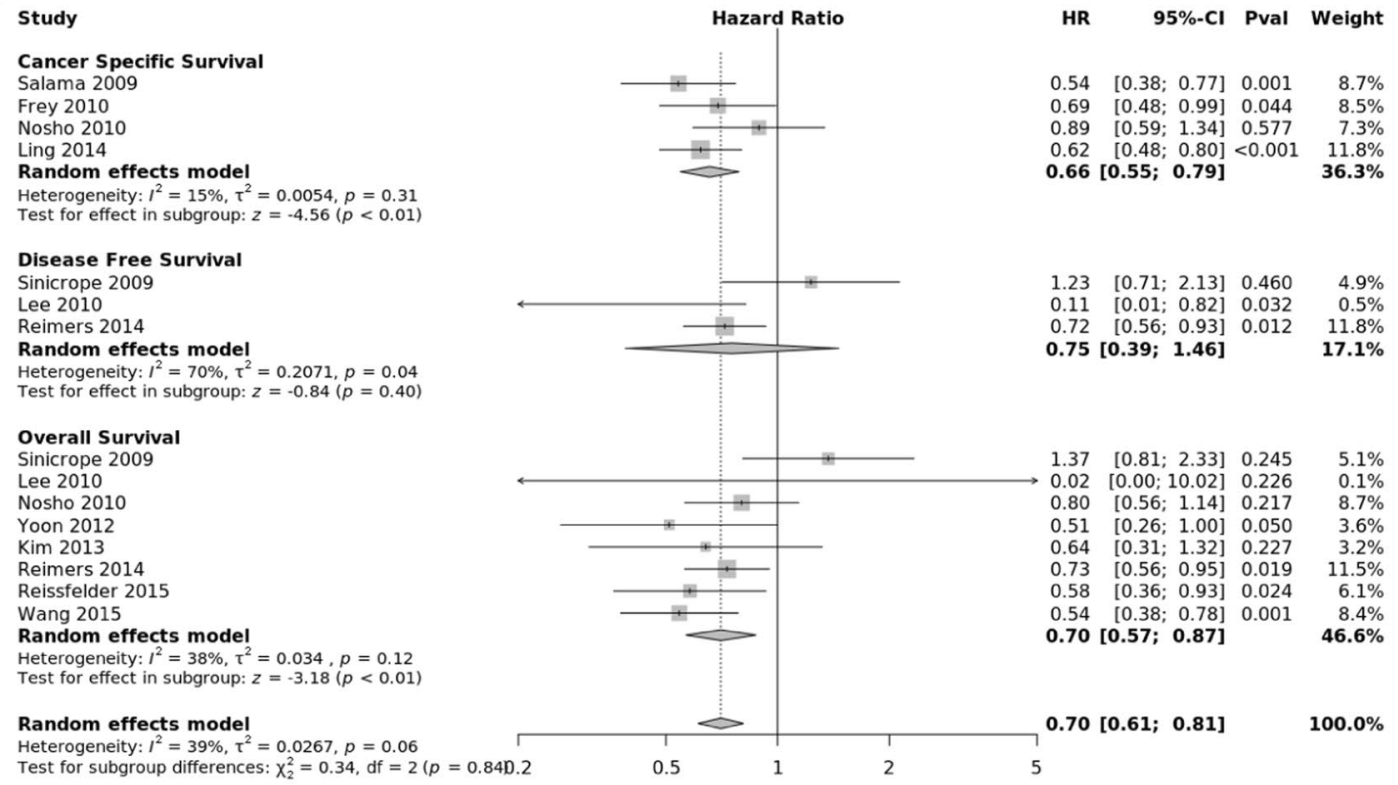

B.

Study

Cancer Specific Survival

Ling 2014

Random effects model

Heterogeneity: not applicable

Test for effect in subgroup: $z=-2.25(p=0.02)$

Overall Survival

Kim 2015

Vlad 2015

Random effects model

Heterogeneity: $I^{2}=0 \%, \tau^{2}=0, p=0.68$

Heterogeneity: $I^{2}=0 \%, \tau^{2}=0, p=0.68$
Test for effect in subgroup: $z=-2.84(p<0.01)$

Random effects model

Heterogeneity: $I^{2}=0 \%, \tau^{2}=0, p=0.79$

Test for subgroup differences: $\chi_{1}^{2}=0.29, \mathrm{df}=1(p=0.59 \mathrm{D} .2$

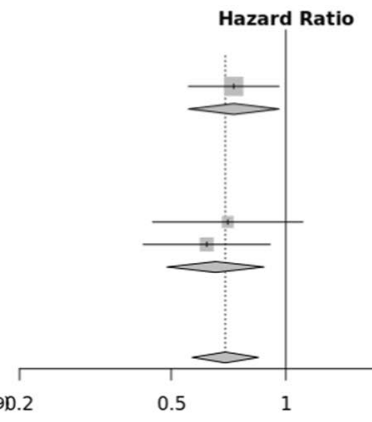

HR 95\%-Cl Pval Weight

$0.73[0.56 ; 0.96] 0.024 \quad 53.4 \%$ $0.73[0.56 ; 0.96] \quad 53.4 \%$

C.

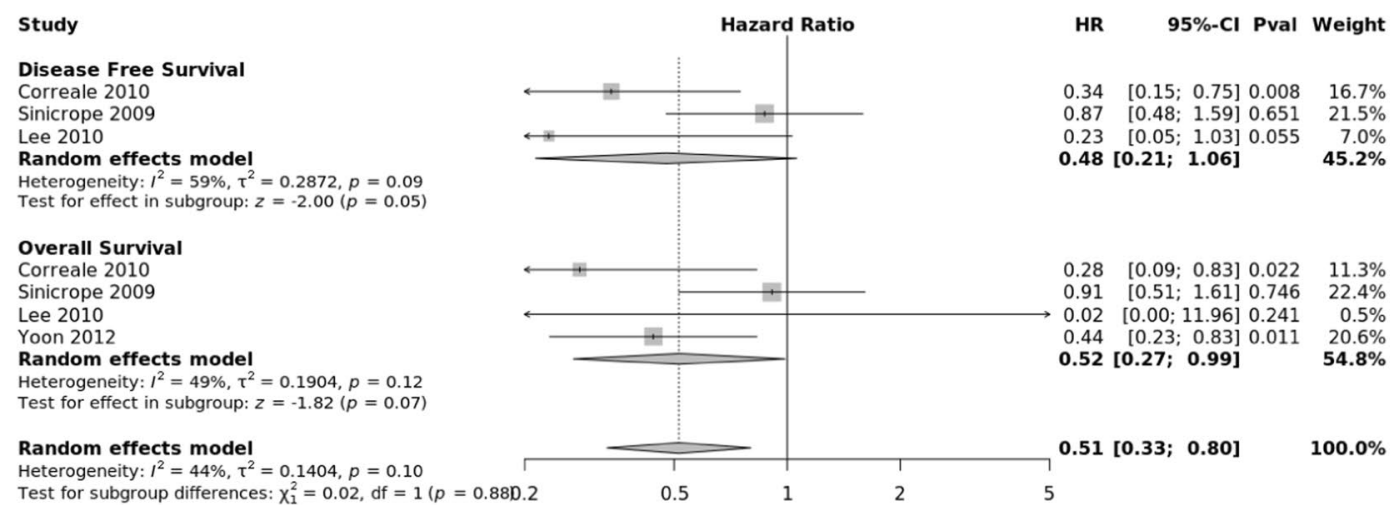

Figure 5. Forest plots of random effects between levels of FOXP3 + T-cell infiltrate and Survival. The effect of FOXP3 + T-cells in the (A) tumor center (B) invasive margin (C) stroma on cancer-specific survival (CSS), disease-free survival (DFS), and overall survival (OS).

(negative or limited) that would modify the estimates. In addition, the different cutoff values for designation of high vs low TIL was a source of bias for this meta-analysis. Among the analyzed studies, the cutoff values included presence or absence (Nagtegaal et al..$^{28}$; Cianchi et al. ${ }^{30}$; Gao et al. ${ }^{32}$; Ogino et al. ${ }^{37}$; Richards et al..$^{50,57}$ ), TIL count with a different threshold for high vs low (Lee et al. ${ }^{44}$; Rozek et al. ${ }^{63}$ ), and mean, media, and quartiles (Naito et al. ${ }^{25}$; Guidoboni et al..$^{27}$; Chiba et al..$^{31}$; Menon et al..$^{33}$; Galon et al. ${ }^{14}$; Salama et al. ${ }^{39}$; Frey et al..$^{43}$; Lee et al. ${ }^{44}$; Nosho et al. ${ }^{45}$; Sinicrope et al..$^{40,64}$; Yoon et al. ${ }^{51}$; Di Caro et al. ${ }^{54}$ ). Some studies detected TILs by tissue microarray while others used full histologic sections. These differences could be responsible for the variability in reaching a 
A.

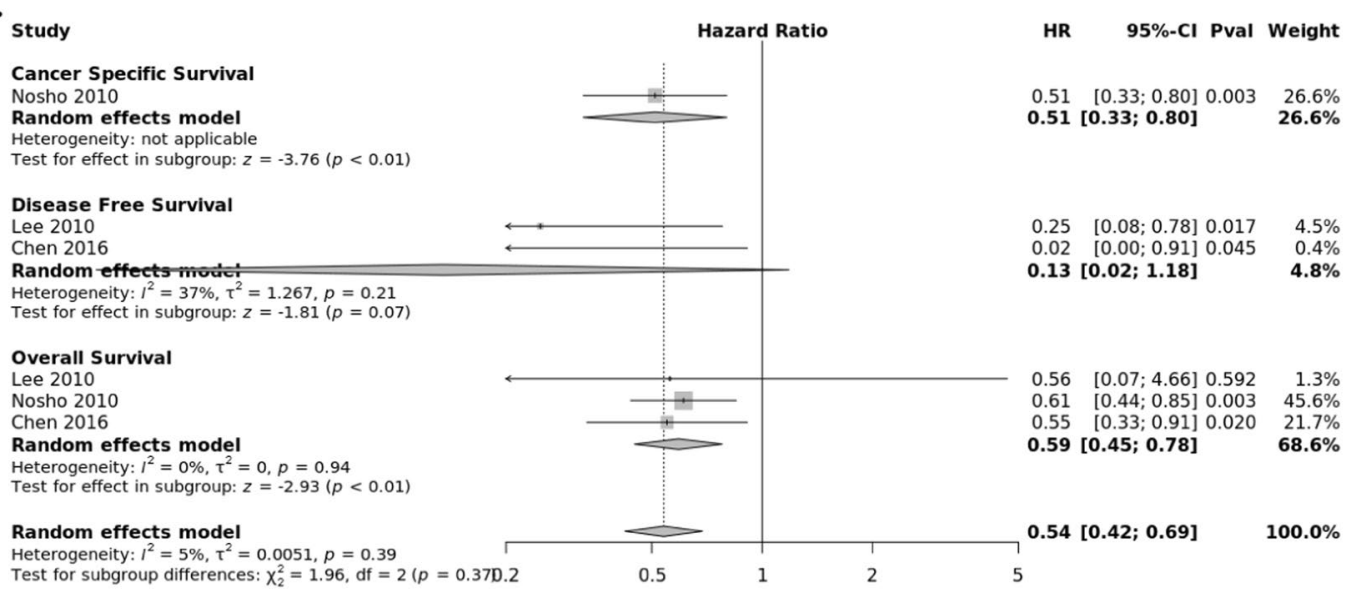

B.

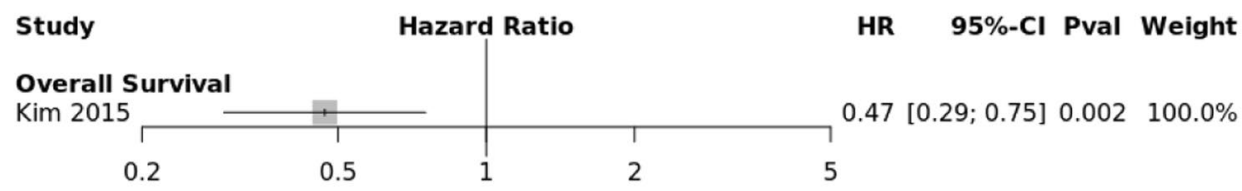

C.

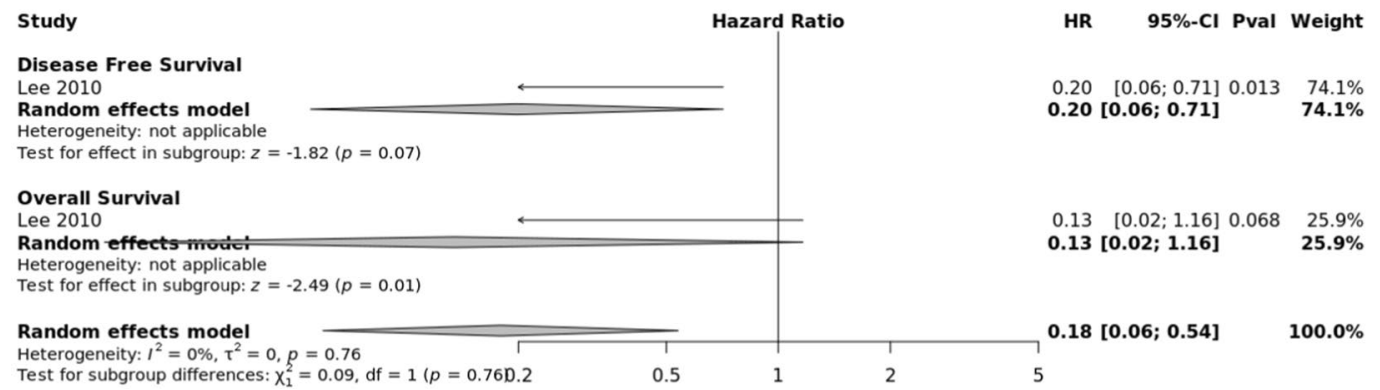

Figure 6. Forest plots of random effects between levels of CD45R0+ T-cell infiltrate and Survival. The effect of CD45R0 + T-cells in the (A) tumor center (B) invasive margin (C) stroma on cancer-specific survival (CSS), disease-free survival (DFS), and overall survival (OS).

standardized method of TIL evaluation. Galon et al. along with other groups including Robins et al. ${ }^{75}$ are making efforts to develop standardized methods to evaluate TILS in order to improve consistency and reproducibility of TIL measurements for future diagnostic studies, yet these techniques have not been broadly adapted enough to summarize with meta-analysis of these specific approaches ${ }^{76}$. Given our results and the extensive literature demonstrating the intratumoral immune cell infiltrate as a highly informative prognostic indicator, further studies are warranted towards the goal of optimizing tumor classification and cancer staging.

Received: 5 March 2019; Accepted: 3 February 2020;

Published online: 25 February 2020

\section{References}

1. Benson, A. B. III et al. NCCN Guidelines Insights: Colon Cancer, Version 2.2018. J. Natl Compr. Canc Netw. 16, 359-369, https://doi. org/10.6004/jnccn.2018.0021 (2018).

2. Gryfe, R. et al. Tumor microsatellite instability and clinical outcome in young patients with colorectal cancer. N. Engl. J. Med. 342, 69-77, https://doi.org/10.1056/NEJM200001133420201 (2000).

3. Drescher, K. M. et al. Lymphocyte recruitment into the tumor site is altered in patients with MSI-H colon cancer. Fam. Cancer 8 , 231-239, https://doi.org/10.1007/s10689-009-9233-0 (2009).

4. Greenson, J. K. et al. Pathologic predictors of microsatellite instability in colorectal cancer. Am. J. surgical Pathol. 33, 126-133, https://doi.org/10.1097/PAS.0b013e31817ec2b1 (2009).

5. Popat, S., Hubner, R. \& Houlston, R. S. Systematic review of microsatellite instability and colorectal cancer prognosis. J. Clin. Oncol. 23, 609-618, https://doi.org/10.1200/JCO.2005.01.086 (2005).

6. Deschoolmeester, V., Baay, M., Lardon, F., Pauwels, P. \& Peeters, M. Immune Cells in Colorectal Cancer: Prognostic Relevance and Role of MSI. Cancer microenvironment: Off. J. Int. Cancer Microenviron. Soc. 4, 377-392, https://doi.org/10.1007/s12307-011-0068-5 (2011). 
7. Hanahan, D. \& Weinberg, R. A. Hallmarks of cancer: the next generation. Cell 144, 646-674, https://doi.org/10.1016/j. cell.2011.02.013 (2011).

8. Abbas, A. K. et al. Regulatory T cells: recommendations to simplify the nomenclature. Nat. Immunol. 14, 307-308, https://doi. org/10.1038/ni.2554 (2013).

9. Gutcher, I. \& Becher, B. APC-derived cytokines and T cell polarization in autoimmune inflammation. J. Clin. investigation 117, 1119-1127, https://doi.org/10.1172/JCI31720 (2007).

10. Banerjea, A. et al. Colorectal cancers with microsatellite instability display mRNA expression signatures characteristic of increased immunogenicity. Mol. cancer 3, 21, https://doi.org/10.1186/1476-4598-3-21 (2004).

11. Mlecnik, B. et al. Histopathologic-based prognostic factors of colorectal cancers are associated with the state of the local immune reaction. J. Clin. Oncol. 29, 610-618, https://doi.org/10.1200/JCO.2010.30.5425 (2011).

12. Pagès, F. et al. Immune infiltration in human tumors: A prognostic factor that should not be ignored. Oncogene 29, 1093-1102, https://doi.org/10.1038/onc.2009.416 (2010).

13. Galon, J. From the immune contexture to the Immunoscore in cancer. Eur. J. Cancer 50, S8, https://doi.org/10.1016/S09598049(14)50030-5 (2014).

14. Galon, J. et al. Type, density, and location of immune cells within human colorectal tumors predict clinical outcome. Sci. 313, 1960-1964, https://doi.org/10.1126/science.1129139 (2006).

15. Galon, J., Angell, H., Bedognetti, D. \& Marincola, F. The Continuum of Cancer Immunosurveillance: Prognostic, Predictive, and Mechanistic Signatures. Immun. 39, 11-26, https://doi.org/10.1016/j.immuni.2013.07.008 (2013).

16. Galon, J. Prognostic markers of the immune system-immune infiltration into the tumour. Eur. J. Cancer 48, 7-8, https://doi. org/10.1016/S0959-8049(12)71810-5 (2012).

17. Ferris, R. L. \& Galon, J. Additional support for the introduction of immune cell quantification in colorectal cancer classification. J. Natl. Cancer Inst. 108, https://doi.org/10.1093/jnci/djw033 (2016).

18. Mei, Z. et al. Tumour-infiltrating inflammation and prognosis in colorectal cancer: systematic review and meta-analysis (Provisional abstract). Br. J. Cancer 110, 1595-1605. http://onlinelibrary.wiley.com/o/cochrane/cldare/articles/DARE-12014012945/frame.html (2014).

19. Moher, D. et al. When and how to update systematic reviews. Cochrane Database Syst Rev, MR000023, https://doi. org/10.1002/14651858.MR000023.pub3 (2008).

20. Moher, D., Liberati, A., Tetzlaff, J., Altman, D. G. \& Group, P. Preferred reporting items for systematic reviews and meta-analyses: the PRISMA statement. Int. J. Surg. 8, 336-341, https://doi.org/10.1016/j.ijsu.2010.02.007 (2010).

21. McShane, L. M. et al. REporting recommendations for tumour MARKer prognostic studies (REMARK). Br. J. Cancer 93, 387-391, https://doi.org/10.1038/sj.bjc.6602678 (2005).

22. Hayes, D. F. et al. Tumor marker utility grading system: a framework to evaluate clinical utility of tumor markers. J. Natl Cancer Inst. 88, 1456-1466 (1996).

23. Cumpston, M. et al. Updated guidance for trusted systematic reviews: a new edition of the Cochrane Handbook for Systematic Reviews of Interventions. Cochrane Database Syst. Rev. 10, ED000142, https://doi.org/10.1002/14651858.ED000142 (2019).

24. Ropponen, K. M., Eskelinen, M. J., Lipponen, P. K., Alhava, E. \& Kosma, V. M. Prognostic value of tumour-infiltrating lymphocytes (TILs) in colorectal cancer. The Journal of pathology 182, 318-324, 10.1002/(SICI)1096-9896(199707)182:3<318::AIDPATH862>3.0.CO;2-6 (1997).

25. Naito, Y. et al. CD8+ T cells infiltrated within cancer cell nests as a prognostic factor in human colorectal cancer. Cancer Res. $\mathbf{5 8}$, 3491-3494 (1998).

26. Nielsen, H. J. et al. Independent prognostic value of eosinophil and mast cell infiltration in colorectal cancer tissue. J. Pathol. 189, 487-495, 10.1002/(SICI)1096-9896(199912)189:4<487::AID-PATH484>3.0.CO;2-I (1999).

27. Guidoboni, M. et al. Microsatellite instability and high content of activated cytotoxic lymphocytes identify colon cancer patients with a favorable prognosis. Am. J. Pathol. 159, 297-304 (2001).

28. Nagtegaal, I. D. et al. Local and distant recurrences in rectal cancer patients are predicted by the nonspecific immune response; specific immune response has only a systemic effect-a histopathological and immunohistochemical study. BMC Cancer 1, 7 (2001).

29. Paraf, F. et al. MLH1 and MSH2 protein immunohistochemistry is useful for detection of hereditary non-polyposis colorectal cancer in young patients. Histopathology 39, 250-258 (2001).

30. Cianchi, F. et al. Lymph node recovery from colorectal tumor specimens: recommendation for a minimum number of lymph nodes to be examined. World J. Surg. 26, 384-389, https://doi.org/10.1007/s00268-001-0236-8 (2002).

31. Chiba, T. et al. Intraepithelial CD8 + T-cell-count becomes a prognostic factor after a longer follow-up period in human colorectal carcinoma: possible association with suppression of micrometastasis. Br. J. Cancer 91, 1711-1717, https://doi.org/10.1038/sj. bjc.6602201 (2004).

32. Gao, J. F., Arbman, G., Wadhra, T. I., Zhang, H. \& Sun, X. F. Relationships of tumor inflammatory infiltration and necrosis with microsatellite instability in colorectal cancers. World J. gastroenterology: WJG 11, 2179-2183 (2005).

33. Menon, A. G. et al. Immune system and prognosis in colorectal cancer: a detailed immunohistochemical analysis. Lab. Invest. 84, 493-501, https://doi.org/10.1038/labinvest.3700055 (2004).

34. Prall, F. et al. Prognostic role of CD8+ tumor-infiltrating lymphocytes in stage III colorectal cancer with and without microsatellite instability. Hum. Pathol. 35, 808-816 (2004).

35. Buckowitz, A. et al. Microsatellite instability in colorectal cancer is associated with local lymphocyte infiltration and low frequency of distant metastases. Br. J. Cancer 92, 1746-1753, https://doi.org/10.1038/sj.bjc.6602534 (2005).

36. Klintrup, K. et al. Inflammation and prognosis in colorectal cancer. Eur. J. cancer 41, 2645-2654, https://doi.org/10.1016/j. ejca.2005.07.017 (2005).

37. Ogino, S. et al. Lymphocytic reaction to colorectal cancer is associated with longer survival, independent of lymph node count, microsatellite instability, and CpG island methylator phenotype. Clin. cancer research: an. Off. J. Am. Assoc. Cancer Res. 15, 6412-6420, https://doi.org/10.1158/1078-0432.CCR-09-1438 (2009).

38. Roxburgh, C. S., Salmond, J. M., Horgan, P. G., Oien, K. A. \& McMillan, D. C. Comparison of the prognostic value of inflammationbased pathologic and biochemical criteria in patients undergoing potentially curative resection for colorectal cancer. Ann. Surg. 249, 788-793, https://doi.org/10.1097/SLA.0b013e3181a3e738 (2009).

39. Salama, P. et al. Tumor-infiltrating FOXP3+ T regulatory cells show strong prognostic significance in colorectal cancer. J. Clin. Oncol. 27, 186-192, https://doi.org/10.1200/JCO.2008.18.7229 (2009).

40. Sinicrope, F. A. et al. Intraepithelial effector $(\mathrm{CD} 3+)$ /regulatory (FoxP3+) T-cell ratio predicts a clinical outcome of human colon carcinoma. Gastroenterology 137, 1270-1279, https://doi.org/10.1053/j.gastro.2009.06.053 (2009).

41. Correale, P. et al. Regulatory (FoxP3+) T-cell tumor infiltration is a favorable prognostic factor in advanced colon cancer patients undergoing chemo or chemoimmunotherapy. J. Immunother. 33, 435-441, https://doi.org/10.1097/CJI.0b013e3181d32f01 (2010).

42. Deschoolmeester, V. et al. Tumor infiltrating lymphocytes: an intriguing player in the survival of colorectal cancer patients. $B M C$ Immunol. 11, 19, https://doi.org/10.1186/1471-2172-11-19 (2010).

43. Frey, D. M. et al. High frequency of tumor-infiltrating FOXP3(+) regulatory T cells predicts improved survival in mismatch repairproficient colorectal cancer patients. Int. J. cancer. J. Int. du. cancer 126, 2635-2643, https://doi.org/10.1002/ijc.24989 (2010).

44. Lee, W. S., Park, S., Lee, W. Y., Yun, S. H. \& Chun, H. K. Clinical impact of tumor-infiltrating lymphocytes for survival in stage II colon cancer. Cancer 116, 5188-5199, https://doi.org/10.1002/cncr.25293 (2010). 
45. Nosho, K. et al. Tumour-infiltrating T-cell subsets, molecular changes in colorectal cancer, and prognosis: cohort study and literature review. J. Pathol. 222, 350-366, https://doi.org/10.1002/path.2774 (2010).

46. Peng, R. Q. et al. Expression of calreticulin is associated with infiltration of T-cells in stage IIIB colon cancer. World J. gastroenterology: WJG 16, 2428-2434 (2010).

47. Simpson, J. A. et al. Intratumoral T cell infiltration, MHC class I and STAT1 as biomarkers of good prognosis in colorectal cancer. Gut 59, 926-933, https://doi.org/10.1136/gut.2009.194472 (2010).

48. Dahlin, A. M. et al. Colorectal cancer prognosis depends on T-cell infiltration and molecular characteristics of the tumor. Mod. Pathol. 24, 671-682, https://doi.org/10.1038/modpathol.2010.234 (2011).

49. Huh, J. W., Lee, J. H. \& Kim, H. R. Prognostic significance of tumor-infiltrating lymphocytes for patients with colorectal cancer. Arch. Surg. 147, 366-372, https://doi.org/10.1001/archsurg.2012.35 (2012).

50. Richards, C. H. et al. The relationships between cellular components of the peritumoural inflammatory response, clinicopathological characteristics and survival in patients with primary operable colorectal cancer. Br. J. Cancer 106, 2010-2015, https://doi. org/10.1038/bjc.2012.211 (2012).

51. Yoon, H. H. et al. Prognostic impact of FoxP3 + regulatory T cells in relation to CD8+ T lymphocyte density in human colon carcinomas. PLoS One 7, e42274, https://doi.org/10.1371/journal.pone.0042274 (2012).

52. Lewis, B. et al. Crohn's disease-like reaction predicts favorable prognosis in colitis-associated colorectal cancer. Inflamm. Bowel Dis. 19, 2190-2198, https://doi.org/10.1097/MIB.0b013e31829e13e1 (2013).

53. Kim, M. et al. Expression of Foxp3 in colorectal cancer but not in Treg cells correlates with disease progression in patients with colorectal cancer. PLoS One 8, e53630, https://doi.org/10.1371/journal.pone.0053630 (2013).

54. Di Caro, G. et al. Occurrence of tertiary lymphoid tissue is associated with T-cell infiltration and predicts better prognosis in earlystage colorectal cancers. Clin. cancer research: an. Off. J. Am. Assoc. Cancer Res. 20, 2147-2158, https://doi.org/10.1158/1078-0432. CCR-13-2590 (2014).

55. Ling, A., Edin, S., Wikberg, M. L., Öberg, Å. \& Palmqvist, R. The intratumoural subsite and relation of CD8+ and FOXP3+ T lymphocytes in colorectal cancer provide important prognostic clues. Br. J. Cancer 110, 2551-2559, https://doi.org/10.1038/ bjc.2014.161 (2014)

56. Reimers, M. S. et al. Prognostic value of HLA class I, HLA-E, HLA-G and Tregs in rectal cancer: a retrospective cohort study. BMC Cancer 14, 486, https://doi.org/10.1186/1471-2407-14-486 (2014).

57. Richards, C. H. et al. The clinical utility of the local inflammatory response in colorectal cancer. Eur. J. cancer 50, 309-319, https:// doi.org/10.1016/j.ejca.2013.09.008 (2014).

58. Kim, J. H., Han, D. S., Bang, H. Y., Kim, P. S. \& Lee, K. Y. Preoperative neutrophil-to-lymphocyte ratio is a prognostic factor for overall survival in patients with gastric cancer. Ann. Surg. Treat. Res. 89, 81-86, https://doi.org/10.4174/astr.2015.89.2.81 (2015).

59. Mori, K. et al. Systemic Analysis of Predictive Biomarkers for Recurrence in Colorectal Cancer Patients Treated with Curative Surgery. Dig. Dis. Sci. 60, 2477-2487, https://doi.org/10.1007/s10620-015-3648-2 (2015).

60. Reissfelder, C. et al. Tumor-specific cytotoxic T lymphocyte activity determines colorectal cancer patient prognosis. J. Clin. investigation 125, 739-751, https://doi.org/10.1172/JCI74894 (2015).

61. Vlad, C. et al. The prognostic value of FOXP3+ T regulatory cells in colorectal cancer. J. B.U.ON.: Off. J. Balk. Union. Oncol. 20, 114-119 (2015)

62. Wang, L., Zhai, Z. W., Ji, D. B., Li, Z. W. \& Gu, J. Prognostic value of CD45RO(+) tumor-infiltrating lymphocytes for locally advanced rectal cancer following $30 \mathrm{~Gy} / 10 \mathrm{f}$ neoadjuvant radiotherapy. Int. J. Colorectal Dis. 30, 753-760, https://doi.org/10.1007/ s00384-015-2226-6 (2015).

63. Rozek, L. S. et al. Tumor-Infiltrating Lymphocytes, Crohn's-Like Lymphoid Reaction, and Survival From Colorectal Cancer. J Natl Cancer Inst 108, https://doi.org/10.1093/jnci/djw027 (2016).

64. Sinicrope, F. A. et al. Association of tumor infiltrating lymphocytes (TILs) with molecular subtype and prognosis in stage III colon cancers (CC) from a FOLFOX-based adjuvant chemotherapy trial. J. Clin. Oncol. 34 (2016).

65. Chen, Y. et al. A Novel Immune Marker Model Predicts Oncological Outcomes of Patients with Colorectal Cancer. Ann. Surg. Oncol. 23, 826-832, https://doi.org/10.1245/s10434-015-4889-1 (2016).

66. Maher, J. \& Davies, E. T. Targeting cytotoxic T lymphocytes for cancer immunotherapy. Br. J. Cancer 91, 817-821, https://doi. org/10.1038/sj.bjc.6602022 (2004).

67. Chaudhary, B. \& Elkord, E. Regulatory T Cells in the Tumor Microenvironment and Cancer Progression: Role and Therapeutic Targeting. Vaccines 4, https://doi.org/10.3390/vaccines4030028 (2016).

68. Shang, B., Liu, Y., Jiang, S. J. \& Liu, Y. Prognostic value of tumor-infiltrating FoxP3+ regulatory T cells in cancers: a systematic review and meta-analysis. Sci. Rep. 5, 15179, https://doi.org/10.1038/srep15179 (2015).

69. Huang, Y. \& Wang, F. M. Prognostic value of tumor-infiltrating FoxP3 + T cells in gastrointestinal cancers: A meta-analysis. J. Digestive Dis. 15, 131, https://doi.org/10.1111/17512980.12194 (2014).

70. Saito, T. et al. Two FOXP3(+)CD4(+) T cell subpopulations distinctly control the prognosis of colorectal cancers. Nat. Med. 22, 679-684, https://doi.org/10.1038/nm.4086 (2016).

71. Grasso, C. S. et al. Genetic Mechanisms of Immune Evasion in Colorectal Cancer. Cancer Discov. 8, 730-749, https://doi. org/10.1158/2159-8290.CD-17-1327 (2018).

72. Cremonesi, E. et al. Gut microbiota modulate T cell trafficking into human colorectal cancer. Gut 67, 1984-1994, https://doi. org/10.1136/gutjnl-2016-313498 (2018).

73. Tran, E. et al. T-Cell Transfer Therapy Targeting Mutant KRAS in Cancer. N. Engl. J. Med. 375, 2255-2262, https://doi.org/10.1056/ NEJMoa1609279 (2016).

74. Jass, J. R. Lymphocytic infiltration and survival in rectal cancer. J. Clin. Pathol. 39, 585-589 (1986).

75. Sherwood, A. M. et al. Tumor-infiltrating lymphocytes in colorectal tumors display a diversity of T cell receptor sequences that differ from the $\mathrm{T}$ cells in adjacent mucosal tissue. Cancer immunology, immunotherapy: CII 62, 1453-1461, https://doi.org/10.1007/ s00262-013-1446-2 (2013).

76. Pages, F. et al. International validation of the consensus Immunoscore for the classification of colon cancer: a prognostic and accuracy study. Lancet 391, 2128-2139, https://doi.org/10.1016/S0140-6736(18)30789-X (2018).

\section{Acknowledgements}

Dr. Idos is a KL2 Scholar awarded through the Southern California Clinical and Translational Science Institute at the University of Southern California, Keck School of Medicine. The project described was supported by the National Center for Advancing Translational Sciences, National Institutes of Health (NIH), through Grant Award KL2TR000131 (GEI); R01 CA197350 (SBG); The Anton B. Burg Foundation; Jane \& Kris Popovich Chair in Cancer Research; Gift from Daniel and Maryann Fong. 


\section{Author contributions}

Study concept and design: Gregory Idos, Nirupama Bonthala, Stephen Gruber. Acquisition of data: Gregory Idos, Nirupama Bonthala, Janet Kwok, Lynn Kysh. Analysis and interpretation of data: Gregory Idos, Stephen Gruber, Chenxu Qu. Drafting of the manuscript: Gregory Idos, Stephen Gruber, Chenxu Qu. Critical revision of the manuscript: Stephen Gruber. Statistical analysis: Chenxu Qu. Obtained funding: Gregory Idos, Stephen Gruber. Administrative, technical, or material support: Stephen Gruber, Lynn Kysh. Study supervision: Stephen Gruber.

\section{Competing interests}

Dr. Gregory Idos has received research funding from Myriad Genetics. Dr. Stephen Gruber has consulted for Myriad Genetics and Fulgent Therapeutics. He has equity ownership interest in Brogent International LLC. Miss. Kysh, Dr. Bonthala, Dr. Kwok, and Dr. Qu declare no potential conflict of interest.

\section{Additional information}

Supplementary information is available for this paper at https://doi.org/10.1038/s41598-020-60255-4.

Correspondence and requests for materials should be addressed to G.E.I.

Reprints and permissions information is available at www.nature.com/reprints.

Publisher's note Springer Nature remains neutral with regard to jurisdictional claims in published maps and institutional affiliations.

(1) Open Access This article is licensed under a Creative Commons Attribution 4.0 International License, which permits use, sharing, adaptation, distribution and reproduction in any medium or format, as long as you give appropriate credit to the original author(s) and the source, provide a link to the Creative Commons license, and indicate if changes were made. The images or other third party material in this article are included in the article's Creative Commons license, unless indicated otherwise in a credit line to the material. If material is not included in the article's Creative Commons license and your intended use is not permitted by statutory regulation or exceeds the permitted use, you will need to obtain permission directly from the copyright holder. To view a copy of this license, visit http://creativecommons.org/licenses/by/4.0/.

(C) The Author(s) 2020 